\title{
The Regional and Cultural Characteristics of B\&B (Bed and Breakfast) Design Against the Background of Traditional Culture - Taking B\&Bs in Yuntai Mountain Area, Henan Province as Examples
}

\author{
Shisheng $\mathrm{Lv}^{1, *}$ Tianhao $\mathrm{Wu}^{1}$ \\ ${ }^{1}$ College of Art and Design, Wuhan Textile University, Wuhan, Hubei 430073, China \\ *Corresponding author. Email: lvgege007@163.com
}

\begin{abstract}
China's economy is in its fast development. From the 20th century to the 21 st century, both social wealth and people's living standards have been unprecedentedly improved. The society began to gradually change from the ideal of production to the ideal of life. After people's material needs have reached a certain level of satisfaction, people began to pay more attention to spiritual pursuits. Among them, tourism is the most common way for people to pursue spiritual pursuits. This behavior, on the other hand, indirectly promotes the development of the tourism industry. With the rapid development of tourism, the construction of accommodation facilities in scenic spots is proceeding simultaneously. In this process, consumers have new demands for tourism. From the original fancy sightseeing tour, they turn to a cultural experience tour that pays more attention to quality. Functions and forms are also undergoing subtle changes, paying more attention to the performance of regional culture. Traditional dwellings and folk customs have a role in the inheritance of regional culture, and they are both carriers of traditional culture. This article uses the transformation of the B\&Bs in Yuntai Mountain area as the research object, starting from the aspects of regional culture, traditional architecture, architectural modeling and space design, and provides a design template method for the Yuntai Mountain area transformation of the B\&B design through the design principles and strategies of the design case.
\end{abstract}

Keywords: Rraditional culture, Regionality, $B \& B$ (Bed and Breakfast) design, Cultural characteristics.

\section{INTRODUCTION}

Today's B\&Bs in China are in their infancy. Except for a small number of high-quality B\&Bs that already have a scale and market, the vast majority of $\mathrm{B} \& \mathrm{Bs}$ are at a relatively early stage in terms of building site selection, interior soft furnishing, architectural modeling and exterior landscape, and most of the design is carried out blindly [1]. The current tourism industry has developed into a white-hot stage, and the experience of rural tourism has become a trend.

B\&Bs in Yuntai Mountain area are common, with single model, lack of design concept, design assimilation, and weak experience. Since the existing B\&Bs in Yuntai Mountain area were mostly farmhouses, small hotels, etc., their design was only a simple imitative transformation of $B \& B s$, and the lack of integration of $B \& B s$ and the local culture behind them made the design of the $B \& B s$ in the area the same, and lost the cultural elements on which the B\&Bs depend for survival.

\section{REGIONAL CHARACTERISTICS ANALYSIS OF YUNTAI MOUNTAIN AREA AND TRADITIONAL DWELLINGS}

\subsection{Geographical Features and Environmental Climate of Yuntai Mountain}

Yuntai Mountain is located in the Taihang Mountains. This area has a typical architectural layout in northern Henan, mostly in the structure of 
triple courtyards or quadrangles, of which the form of triple courtyards is the most common. The triple courtyard is a traditional courtyard house in the countryside of China. This kind of layout is divided into two types: closed type and open type, and the building materials are also determined by the local location. This kind of architectural layout consists of three houses forming a concave-shaped plane, consisting of a rectangle and the remaining two symmetrical and backside houses on both sides [2]. The triple courtyard consists of three main rooms, the house occupying the middle becomes the main room, and the east and west rooms become the wing rooms. The eaves in front of the main house can be extended. A series of natural activities such as eating and resting can be carried out under the eaves [3]. The doors of the wing rooms are smaller than that of the main room. The two ends are connected by a wall, and there is a door in the middle of the wall opens to the south.

\subsection{The Vernacular Characteristics of Building Materials}

Yuntai Mountain is rich in original ecological natural resources, which can be roughly divided into three categories: animal, plant, and mineral resources. The main raw materials for construction are plants and minerals. Plants are mainly cypress trees, fringed trees, etc. Among them, cypress trees are most used in traditional buildings to bear the main load-bearing role of houses [4]. They are used in large quantities in this area. As Yuntai Mountain area has a typical temperate continental climate with high winds, the main materials for the facades of the houses in this area are all locally sourced,

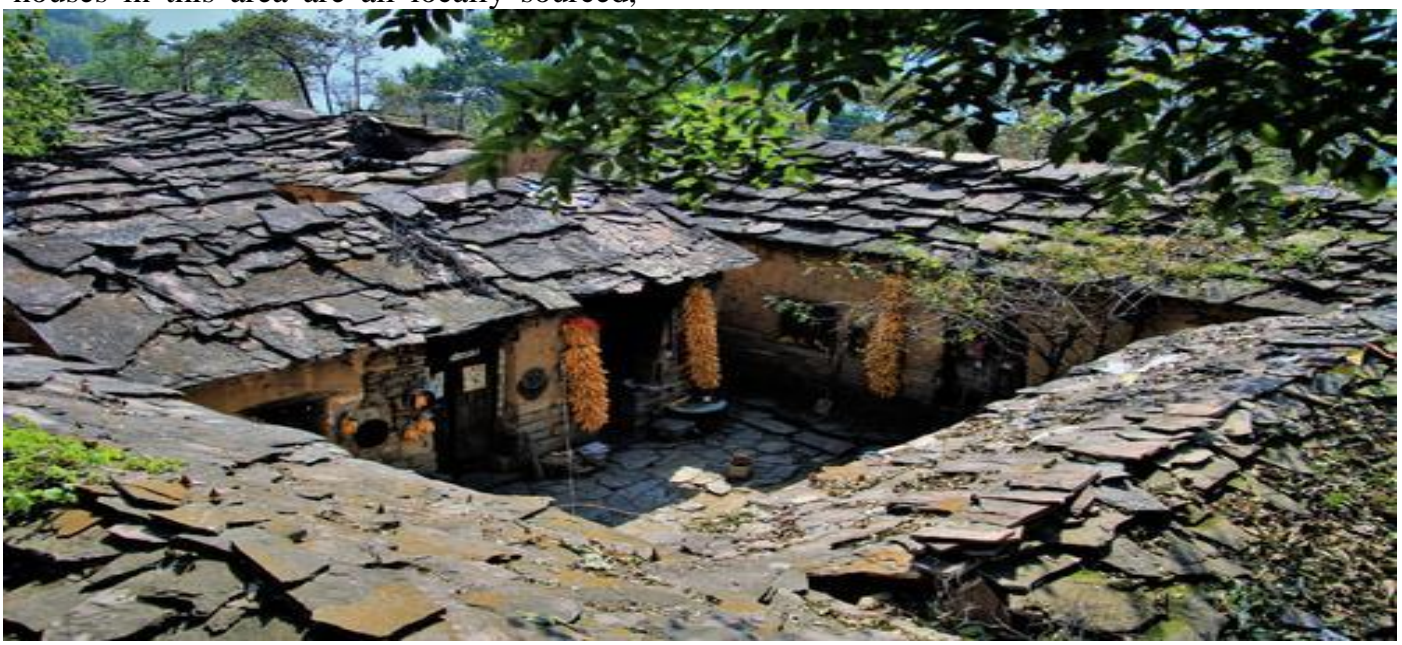

Figure 1 Traditional slate houses in Yuntai Mountain area. and the most common slate and stones are used as building materials. On the one hand, this material was selected because Yuntai Mountain area is a mountainous area, and the production of stone materials according to local conditions can greatly reduce the construction cost. On the other hand, the stone has high stability and wind resistance, which can withstand the windy weather in the area [5]. The internal structure of the building uses cypress as the structural support to enhance the stability of the building structure. The slate houses are built with stone walls and covered with stone slabs. Local materials are used to create characteristic slate houses. In ancient times, the mountain roads were rugged and transportation was extremely inconvenient. The bricks and tiles under the mountain were difficult to transport to the mountain, and the stone covered with the mountain became the best substitute [6]. Most of the slate houses use slate as the foundation. They are built according to the mountain and topography, scattered and durable. The slate house, as a simple building, does not add any decorations, and is integrated with the surrounding mountains and forests. Because the slate does not store water and the water slides quickly, it can protect the internal wood from rot due to water erosion [7]. It is warm in winter and cool in summer, sturdy and durable. Stone has good thermal insulation. In winter, residents in this area will set fires in the house, and the thermal insulation of the stone will be fully utilized, and the whole house will be full of warmth. The slate house as shown in "Figure 1" has a strong regional character, not only of practical value but also of historical research value. 


\subsection{Color and Decoration of Building Materials}

The color of building materials is generally not decorated, but the original color of the material is directly used to maintain the original property of the material. The original texture of stone or wood is exposed to make the building more natural and consistent with the surrounding environment. The natural attributes are preserved without any reservation [8]. As a building form with the best preservation of natural attributes, the slate house is a natural framing in terms of decoration, using surrounding vegetation as decoration without excessive human intervention. In the harvest season, due to the stability of the slate house and the flatness of the slate roof, people will put the harvested crops on the roof for drying [9]. Due to the different crops, the color will be different, which will form the unique humor of the slate house, which is also a unique decoration.

\section{PRINCIPLES OF DESIGN AND RECONSTRUCTION OF B\&BS IN YUNTAI MOUNTAIN AREA}

\subsection{Principles of Regional Cultural Inheritance}

A good design needs cultural background as support and support to be regarded as a good design work. It must fully retain the regionality and culture of the area. The Yuntai Mountain area is located in the Central Plains region and has a profound cultural background and historical heritage, which the designers must grasp for the design. When a design work is displayed to people, it is necessary to give the design a good cultural support. Regional culture is the most primitive quality and characteristic that the regional environment gives to the culture. These characteristics will not fade with the development of the times, on the contrary, they will burst out with stronger vitality and vitality afterwards [10]. And from a cultural point of view, regional cultures are the external and internal manifestations of the diversity of ethnic cultures. The influence of regional culture on architecture is also subtle, and the various architectural styles of different styles and schools formed by regionality in China are very good proof. Therefore, it should be upheld when carrying out the renovation and design of the $\mathrm{B} \& \mathrm{~B}$. The designers should find the perfect balance between the traditional and the modern, so that the two can coexist in order to better carry forward the traditional culture, and at the same time create a more cultural design and better improve life.

\subsection{Principles of Diversity Experience}

The $\mathrm{B} \& \mathrm{~B}$ serves as an important window to showcase the regional culture. The primary factor that people consider when choosing a B\&B is to allow tourists to fully feel the unique regional cultural charm of the area. The creation of the overall space atmosphere of the $B \& B$ mainly depends on the refinement of the regional cultural symbols of the area, which enable tourists to feel the regional cultural characteristics of the area in the most direct way. The design of the $\mathrm{B} \& \mathrm{~B}$ should also follow the principle of diversity experience, starting from the spatial layout, interior decoration, color matching, etc., and integrating with regional cultural symbols from many aspects.

\subsection{Principles of Ecological and Environmental Protection}

In traditional Chinese Confucianism, man and nature should be in a symbiotic relationship. With the development of the times, the pace of urbanization is getting faster and faster [11]. Buildings made of reinforced concrete have gradually become the mainstream and become the darling of this fast era. There is no green in the building. Yuntai Mountain, as a tourist resort area, receives most of the passenger flow from the cities. Such tourists live in the city for a long time among the tall buildings, and they need more green design to introduce plants into the buildings. Only by bringing tourists a unique experience can they attract tourists more and satisfy their spiritual pursuits while also improving and protecting the environmental protection of the surrounding ecology.

\section{B\&B RENOVATION IN YUNTAI MOUNTAIN AREA}

\subsection{Architectural Modeling and Space Design}

When constructing a regional homestay building, it is necessary to consider highlighting the regionality and the inheritance of traditional culture, while at the same time integrating modern design concepts into it, so that the B\&B has a modern feel. 

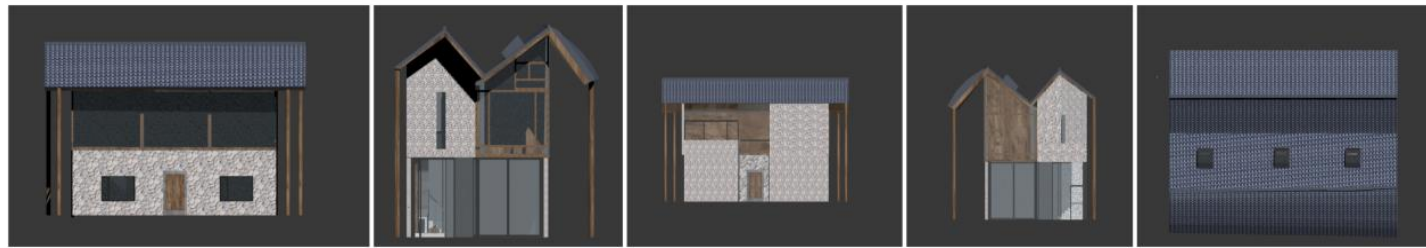

Figure 2 The facade view of the B\&B building.

As shown in "Figure 2", the design of this B\&B is based on the slate house in Yuntai Mountain area, highlighting the regional characteristics, and chooses the same materials as the traditional slate house in the selection and application of building materials.

The main material of the building adopts the most common stone slabs in the area, and also fully retains the original attributes of the stone, fully retaining its natural texture, making the building closer to the traditional style. Like traditional buildings, the most common cypress in the area is used as the main wood.

The whole building retains the tradition while using modern glass and stainless steel to reveal a sense of modern design in the tradition. The whole building still adopts the construction concept of integrating with nature. The use of four cypress trees as support plays a supporting role on the one hand, and on the other hand, they can also play a good aesthetic effect. The entire building has a series of modern designs while retaining the traditional architectural style.

The traditional brick-and-tile design used in the eaves of the entire building not only makes the building more beautiful, but also makes the building more modern and traditional. The eaves are treated with an extended approach, and a series of activities such as eating and resting under the eaves are generally available for the main house of

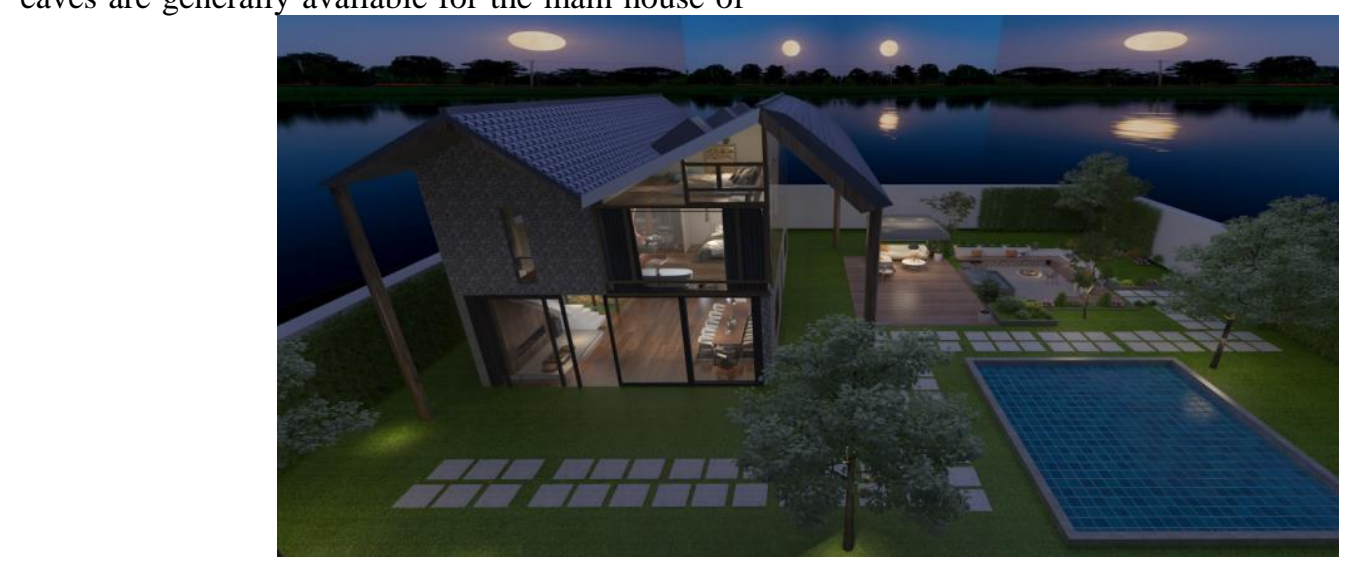

Figure 3 The rendering of the exterior space of the B\&B. a traditional triple courtyard. Viewed from the front, the eaves are exactly the same as the traditional square-shaped eaves. Viewed from the side, the entire eaves presents an arc shape from left to right and lower to the right. The entire eaves presents a rising trend of the mountain rising from left to right. On the one hand, it creates a sense of illusion, and on the other hand, it responds to the trend of the mountain and makes the building more integrated into the environment. The shape of the roof ridge from the top view clearly shows this trend. Modern floor-to-ceiling glass windows are used on the left and right sides of the building to make light shine better, forming a transparent space. The entire building uses traditional building materials and shapes while taking into account the use of modern elements. The entire building is divided into two floors. The space on the first floor is mainly for public activity areas, and the second floor is for accommodation areas. The clear division of areas allows visitors to have a better experience.

On the second floor of the building used as the accommodation area, the best direction of sunlight is designed as the location of the guest rooms, and the three guest rooms are closely connected, which not only enhances the interaction and linkage, but also enables the guests who come to stay to get better experience. The independent outdoor space and environment design of the $\mathrm{B} \& \mathrm{~B}$ is also very important. 
As shown in "Figure 3", a sunken outdoor open living room is designed on the right side of the entire building, so that people can get closer to nature, and the sunken layout can give people a more comfortable and novel experience. There are three important principles for outdoor environment expression, namely continuity, authenticity and suitability. In this design, green is introduced into the yard and paving stones are set to guide the direction while ensuring the integrity of the vegetation to the greatest extent. The entire outdoor living room uses wood color to make the inside and outside of the house echo each other at a distance, but also makes people feel like being in nature. The huge swimming pool on the left is made of fairfaced concrete with the most modern design, and the bottom is made of blue tiles with different colors, forming a modern design sense, making the entire yard not only have traditional regionality in it, but also distribute the breath of structuralism in every corner of the yard.

\subsection{Interior Design}

In the design of $\mathrm{B} \& \mathrm{Bs}$, it is necessary to try a non-programmatic design concept, break the conventional design method, return to the design language of self-occupation, and create an interior architectural design method that integrates with the regional culture. It must be in line with the hearts of the coming consumers. Most of the tourists who come to play want to experience a new layout and the feeling of embracing nature. As shown in "Figure 4", the public area greatly breaks the traditional interior design style, creating a feeling of openness. The overall color is wood and white, and the wood color is mainly brown, one light and one dark, echoing each other to form a sense of gap. On the opposite side of the entrance, a glass is used to create a patio to bring plants into the building. This fully complies with the concept of green design, and also allows visitors to get a new experience. The chandelier on the top adopts a minimalist design, and the bones of the metal frame collide with black and white.

The guest rooms on the second floor all adopt warm white and wood colors as shown in "Figure 5". They all adopt floor-to-ceiling windows to obtain the best scenery and light under the premise of ensuring privacy. The entire room is decorated with warm colors and chandeliers. The contrast of wood color and warm light makes the room more unique. A touch of pink grille not only highlights the modern design, but also adds a bit of fun to the room. And a loft is placed on the top of the room, not only can the tourists experience different feelings, but they can also enjoy the sky through the skylight reserved on the roof.

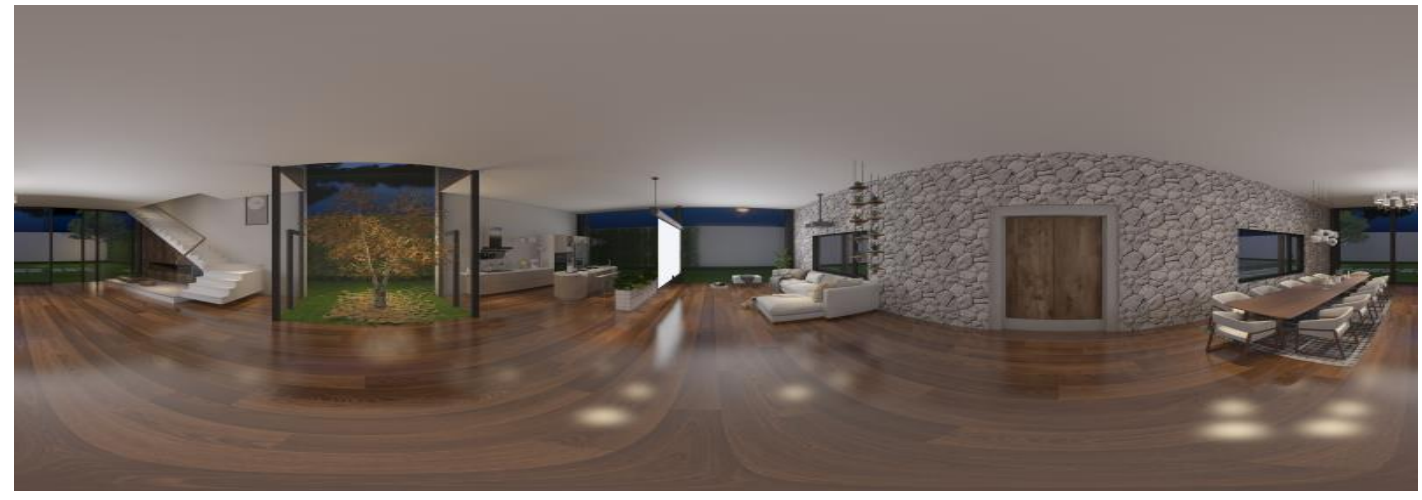

Figure 4 The effect of the first floor space of the B\&B.

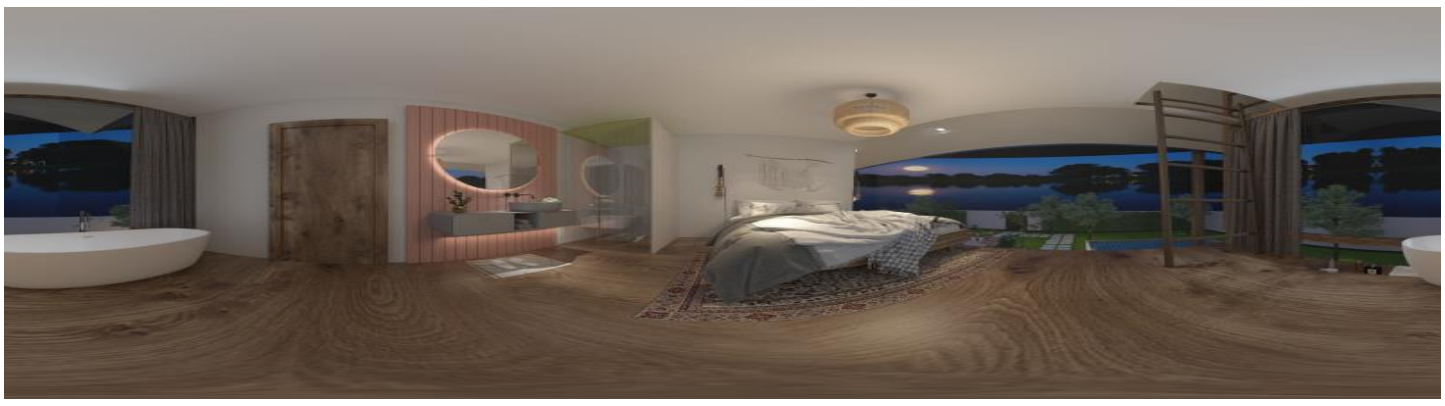

Figure 5 Rendering of guest room on the second floor of a B\&B. 


\section{CONCLUSION}

Due to the special nature of regional culture, the discussion in this article is not suitable for all modern $\mathrm{B} \& \mathrm{~B}$ designs. And because the design of the $\mathrm{B} \& \mathrm{~B}$ is full of subjectivity, higher requirements are put forward for the designer's design ability and cultural literacy. These requirements have become an important basis for considering whether the design of the $\mathrm{B} \& \mathrm{~B}$ incorporates regional cultural elements.

Firstly, it is necessary to summarize and sort out the existing problems and needs of B\&Bs in the area, and then analyze the geographical, cultural, and emotional factors of the area. Geographical location is the most important thing [12]. The first consideration in the design of a $\mathrm{B} \& \mathrm{~B}$ is the location. Therefore, the beginning of the $\mathrm{B} \& \mathrm{~B}$ design is to analyze the region. The region not only includes the surrounding environment of the location, but also considers the local conditions and customs.

Then, the designers need to use the Delphi method and brainstorming method to refine the regional cultural symbols from the three levels of form, consciousness, and spirit.

Finally, the refined cultural symbols should be optimized with the selection of local unique materials, color matching, and space fusion furnishings, and some reorganization and optimization need to be carried out to select symbols suitable for modern B\&B design. And then, the integration of different combinations can be carried out to complete the design of the B\&B.

"New" and "old" are originally two opposite sides, and the two mutually reinforce each other. The old is more about the oldness and age of the object itself, while the new is about new materials and new technologies. The design of the $\mathrm{B} \& \mathrm{~B}$ is not only to design a house, but to put people first and design an attitude of life style. It not only has to show distinctive regional cultural characteristics, but also requires continuous innovation through modern people's designs. In the interior design, modern new elements can be used to form a sharp contrast with the "old" of the building. The local customs and new design concepts can be injected into the room [13]. Designers can use modern glass and stainless steel to separate geometric figures, echoing the original architectural shape, which not only have the characteristics of freehand oriental framed sceneries, but also create the situation of moving and different sceneries. Under the premise of fully respecting the environment, combining traditional regional culture with new materials, architecture and natural landscapes should echo and perceive each other. The authors hope that as one situation and one environment running through the whole text, and the three small points producing common thinking within a certain range, this article can provide enlightenment for the future design of homestays in this area.

\section{AUTHORS' CONTRIBUTIONS}

Shisheng Lv analyzed data and contributed to revising and editing; Tianhao $\mathrm{Wu}$ was responsible for experimental design and wrote the manuscript.

\section{REFERENCES}

[1] Kang Lizhi. Application of regional culture in $\mathrm{B} \& \mathrm{~B}$ interior design $[\mathrm{J}]$. Architectural economics, 2020,41 (10): 159-160. (in Chinese)

[2] Jiang Mengfei, Lu Ya. Study on regional characteristics of rural tourism homestay design around the city based on Chengdu [J]. Green technology, 2020 (19): 165-167. (in Chinese)

[3] Yan Chenyue. Inspiration analysis of B \& B space design in Moganshan area [J]. HOS, 2020 (29): 107-108. (in Chinese)

[4] Shang Yanyun. Expression of modernity in regional B \& B architectural design [J]. New building materials, 2020,47 (10): 183-184. (in Chinese)

[5] Liu Min. research on the application of regional cultural elements in B \& B space design [J]. Hosshe, 2019 (19): 94. (in Chinese)

[6] Luo Ruijuan. Application of regional cultural elements in the interior design of B \& B [J]. Theatre house, 2020 (27): 184-185. (in Chinese)

[7] Zhang Yan. Space design of B \& B building under regional culture background [J]. Building materials and decoration, 2020 (14): 91-95. (in Chinese)

[8] Chen Jingping. Application and research of regional cultural elements in B \& $\mathrm{B}$ interior design [J]. Sichuan cement, 2019, (07): 81. (in Chinese)

[9] Liu Kai. On the regional cultural characteristics of $\mathrm{B} \& \mathrm{~B}$ design under the 
background of tourism [D]. Yunnan University of Arts, 2020. (in Chinese)

[10] Yang Yang. Exploring the significance of the combination of $\mathrm{B} \& \mathrm{~B}$ interior design and local culture [J]. Daguan, 2020 (11): 49-50. (in Chinese)

[11] Guo Lixian. Application of traditional cultural elements in B \& B design [J]. Architectural economics, 2020, 41 (10): 147-148. (in Chinese)

[12] Dong Jing. Application of natural decorative elements in the interior design of $\mathrm{B} \& \mathrm{~B}[\mathrm{~J}]$. Art education research, 2020 (17): 78-79. (in Chinese)

[13] Liu Zhixian. Characteristics and innovation of B \& B tourism landscape design [J]. Housing and real estate, 2020 (18): 64-65. (in Chinese) 